\title{
Clinical Oversea Internship Experience Among Nursing Students
}

\author{
Sun A Whang \\ Department of Nursing, Semyung University, Korea \\ winnersmile@hanmail.net
}

\begin{abstract}
In this paper provides an in-depth phenomenological description and identification of the short international internship experiences of Korean nursing students. Eight students were selected by means of theoretical sampling and the data were collected from personal, indepth interviews. Twelve theme clusters and five categories were identified from five categories: 1) Reliable hospital system, 2) Environments where nurses can demonstrate competence as professionals, 3) Hospital where nurses love to work, 4) Motivation for learning, 5) The frog that came out of the well. These results show that short-term clinical oversea internship program of nursing students have provided to be an effective program that can provide motivation and broad perspective to competence as nursing profession. Therefore, it is necessary for many students to experience various internship programs for nursing students.
\end{abstract}

Keywords: Nursing, Student, Oversea, Internship, Qualitative, Research, Experience

\section{Introduction}

\subsection{Backgrounds}

Internship abroad is not just an empirical [1] but also situational [2] study where students can apply what they have learned at school to the field and experience it. Also, the international internship program, designed to influence their career and strengthen their competitiveness in the job market, provides not just knowledge and techniques through field training related to their major but also opportunities to improve their competitiveness to adjust into a new culture and to improve language skills [3]. Therefore, many other departments of colleges in Korea are running such internship abroad as well.

In the case of international internship, each college provides a different period of programs. The preliminary research related to the internship programs abroad for nursing students examined students who went through a four-month internship, which amounts to one semester. And, as its results showed different cases, including some said positively [4] and others negatively [5], depending on research, the follow-up studies are needed so that researchers can find out where they should find out such difference. Also, it is unprecedented to conduct research on one-month international internship programs. Therefore, it is necessary to start empirical studies on a short-term clinical oversea internship for nursing students.

Article history:

Received (October 26, 2017), Review Result (November 15, 2017), Accepted (February 2, 2018) 


\subsection{Purpose of study}

This paper is to provide research materials basis for developing international clinical training programs in the future by identifying experience of short-term international internships among nursing students. To that end, the main agenda of this study should be "What do nursing students experience from a short-term clinical oversea internship?"

\section{Methodology}

\subsection{Design}

This study is a qualitative research based on phenomenological methodology to identify experience of short-term clinical oversea internship of nursing students.

\subsection{Participant}

The participants of this study were selected based on intentional as well as convenience samplings. They are 19 students in total, and among them, seventeen were female students, consisting of students in their junior and senior years, who understood the purpose of this study and agreed to participate in it among those selected for internship programs at the hospital in the U.S., and experienced a four-week internship while majoring in nursing of $S$ University.

\subsection{Data collection}

Before collecting data, researchers went through IRB assessment of the organization where they belong, and received its approval. Two researchers had one-on-one interview with each participant from October 2017 to January 2018 in order to collect data. Participants were recruited by posting a notice on a bulletin board of the nursing department of S University. They informed participants that the substance of the interviews will be used only for the study.

The interviews were conducted at a quiet time and place so that the participants can continue their conversation. All the interviews were recorded and researchers repeatedly listened to the recorded files in order to transcribe the exact words the participants used. Also, they wrote down the non-verbal expressions, like facial expressions of the participants, their feelings and what the researchers felt of the participants.

And, by asking "Please tell me about your short-term international internship you had for four weeks" during the interview, the researchers tried to communicate with the participants with consistent interest and encouragement onto their experience.

\subsection{Data analysis}

This study analyzed the internship experience of nursing students at the hospital in the U.S. based on the phenomenological method as Colaizzi [6] suggested. It is to extract significant sentences or phrases from what the participants stated, collect general and abstract statement based on them, find out meanings, categorize them by theme clusters, and describe the substantial structure of the experience. And then, the researchers again check its validity with the participants. Since the themes reflect the meaning, the overall process helps to embrace themes without any prejudice.

\subsection{Training process}


The researchers completed the qualitative method at the graduate school as educational preparation for their study. And, they continued to study literatures related to the theories and actuality and took part in workshops. There are papers they wrote by applying qualitative method to.

\section{Results}

As a result, from analyzing the meaning of the short-term international internship which nursing students completed, there were five categories, 12 clusters of themes, 24 themes, and 152 significant statements [Table 1].

Table 1. Categories, theme clusters, and themes of short-term international internship of nursing students

\begin{tabular}{|c|c|c|}
\hline Categories & Theme clusters & Themes \\
\hline \multirow{4}{*}{$\begin{array}{l}\text { Reliable hospital } \\
\text { system }\end{array}$} & \multirow{2}{*}{$\begin{array}{l}\text { Nursing with rigorous } \\
\text { administration }\end{array}$} & Using the barcode for medication administration \\
\hline & & $\begin{array}{l}\text { Providing detail information when administering } \\
\text { medication }\end{array}$ \\
\hline & \multirow{2}{*}{$\begin{array}{l}\text { Rigorous infection } \\
\text { management }\end{array}$} & Using disposable products \\
\hline & & Using single patient rooms \\
\hline \multirow{6}{*}{$\begin{array}{l}\text { Environments where } \\
\text { nurses can demonstrate } \\
\text { competence as } \\
\text { professionals }\end{array}$} & \multirow{2}{*}{$\begin{array}{l}\text { Environment without any } \\
\text { suppression }\end{array}$} & Casual outfit \\
\hline & & Liberal and unsupervised working environments \\
\hline & \multirow{2}{*}{$\begin{array}{l}\text { Being able to provide } \\
\text { comprehensive nursing } \\
\text { care }\end{array}$} & Having a small number of patients to be responsible for \\
\hline & & Having time on his/her side \\
\hline & \multirow{2}{*}{$\begin{array}{l}\text { Nurses working with high } \\
\text { self-esteem }\end{array}$} & Being trusted by patients \\
\hline & & Having a level playing field with other medical teams \\
\hline \multirow{6}{*}{$\begin{array}{l}\text { Hospital where nurses } \\
\text { love to work }\end{array}$} & \multirow{3}{*}{$\begin{array}{l}\text { Hospital where everyone } \\
\text { is respected }\end{array}$} & Respected patients \\
\hline & & Respected nurses \\
\hline & & Respected nursing students \\
\hline & \multirow{3}{*}{$\begin{array}{l}\text { Bright and liberal } \\
\text { atmosphere }\end{array}$} & Having a smiling face all the time \\
\hline & & Greeting with people you have just met \\
\hline & & No hazing practice, called "taewoom" \\
\hline \multirow{6}{*}{ Motivation for learning } & \multirow{2}{*}{$\begin{array}{l}\text { Being motivated to study } \\
\text { nursing }\end{array}$} & The more you know, the more you can see \\
\hline & & Importance of medical terms \\
\hline & \multirow{2}{*}{$\begin{array}{l}\text { Being motivated to study } \\
\text { English }\end{array}$} & Being frustrated by uneasy communication \\
\hline & & Being satisfied when talking to foreigners \\
\hline & \multirow{2}{*}{$\begin{array}{l}\text { Experience during the } \\
\text { internship serves as a } \\
\text { steppingstone }\end{array}$} & Being proud \\
\hline & & Wishing to recommend to juniors \\
\hline \multirow{4}{*}{$\begin{array}{l}\text { The frog that came out } \\
\text { of the well }\end{array}$} & \multirow{2}{*}{$\begin{array}{l}\text { Realizing that there's } \\
\text { more about being nurse } \\
\text { except nurses in Korea }\end{array}$} & Witnessing ideal nurses in the U.S. \\
\hline & & $\begin{array}{l}\text { Being able to compare clinical practice in Korea to that } \\
\text { in the U.S. based on internship abroad }\end{array}$ \\
\hline & \multirow{2}{*}{$\begin{array}{l}\text { Having confidence of my } \\
\text { dream to be a nurse }\end{array}$} & Being proud of being a nurse \\
\hline & & Dream of being a nurse in the U.S. \\
\hline
\end{tabular}


This chapter is to identify the relevance among the themes of short-term clinical oversea internship nursing students experienced and enhance understanding of the context based on their interviews.

\subsection{First category: Reliable hospital system}

\subsubsection{Theme cluster: Nursing with rigorous administration}

You can scan the barcode of medication carts and check their information in advance. And, if you scan the barcode of medication without making any error, the system gives you the exact medication you want so that you can pick it up... (Participant 1).

Nurses in the U.S. have more time on their side compared to nurses in Korea. So, they provide better explanation for patients. In many cases of oral medication, we simply said "take it" and left. But, nurses in the U.S. explained all the medications one by one (Participant $3)$.

\subsubsection{Theme cluster: Rigorous infection management}

Although there were many consumables as nurses used disposable products even for kits, I thought it is good to manage infection (Participant 5).

Rooms are single patient rooms. So, I thought because of that there was no infection. Hospital bills were expensive though... (Participant 4).

\subsection{Second category: Environments where nurses can demonstrate competence as} professionals

\subsubsection{Theme cluster: Environment without any suppression}

We care much about how we appear while they seemed to ... (Interruption) focus only on nursing without caring about their external style... (Participant 8).

It seemed that I felt working there more comfortable. Compared to working in the suffocated environments, I thought it is better atmosphere where I can freely communicate with others (Participant 2).

\subsubsection{Theme cluster: Being able to provide comprehensive nursing care}

You can focus on one or two patients that you are in charge of all day long, know what they want, and be very much close to them (Participant 8).

\subsubsection{Theme cluster: Nurses working with high self-esteem}

Not just patients, but also others highly trusted nurses. (Participant 8).

Doctors and nurses treated each other equally. I heard that Korea has duty concept for many cases, like interns or residents on duty. But, the U.S. does not. Rather nurses are the ones who stay all the time... (Participant 8).

\subsection{Third category: Hospital where nurses love to work}

\subsubsection{Theme cluster: Hospital where everyone is respected}


In Korea, the system of hospitals comes first than patients. However, I felt that in the U.S., patients come first, and then, the system was facilitated for the patients (Participant 5).

It was good to see that they freely communicate with one another mostly and give a little bit more respect for nursing students without ignoring them... (Participant 2).

\subsubsection{Theme cluster: Bright and liberal atmosphere}

Since I attended every day, I found something different from Korea, which is first they always greeted people and smiled to them once their eyes met. (Participant 7).

I saw a newly joined nurse leaning on one foot with her arms folded when talking to a preceptor. It was like a cultural shock to us... (Participant 2).

\subsection{Fourth category: Motivation for learning}

\subsubsection{Theme cluster: Being motivated to study nursing}

I believe that you will learn a lot if you study more before the internship (Participant 1).

When it comes to the kidney for example... it was more helpful as I understood it all together with kidney dialysis in the U.S. and in the Korea... (Participant 2).

You can understand the work in the hospital at some levels if you study medical terms before (Participant 5).

\subsubsection{Theme cluster: Being motivated to study English}

It was a bit sad that I cannot communicate well (Participant 3).

I felt interesting in speaking English for the first... and in the end, it seemed that I was able to understand a lot when listening... (Participant 2).

\subsubsection{Theme cluster: Experience during the internship serves as a steppingstone}

I don't know why, but it seems like I am always proud of myself (Participant 2).

I always talk to my juniors who hesitate over internship that they must go. Therefore, there are many who love to do the internship. Even I myself did not have a clear reason to go. But it truly helped me to realize, learn, and reorganize my thoughts a lot... (Participant 5).

\subsection{Fifth category: The frog that came out of the well}

\subsubsection{Theme cluster: Realizing that there's more about being nurse except nurses in Korea}

I witnessed the real picture of being nurse, which I really want. She always smiled and worked truly for the patients. It's annoying to frequently sterilize and others. But, that nurse sincerely cared her patient while saying "No, sterilization is important even the patient is unconscious. It stinks a lot, isn't it? But, it's OK." (Interruption)... That is exactly what I really want (Participant 4).

I could compare the two cases in the U.S. to Korea as I went abroad after going through clinical training in Korea once (Participant 1).

\subsubsection{Theme cluster: Having confidence of my dream to be a nurse}

I had simply thought that I would be a nurse in Korea after graduating nursing college. But, after the internship, I realized that I could work like this in overseas (Participant 3). 
Anyway, I did internship. So, it made me have positive position on the job of nurses more. (Interruption) I thought that this is what they do for the patient. With that, I thought it would be good to be a nurse just like the ones I saw in the U.S., who listen carefully to patients and communicate with them well (Participant 5).

\section{Discussion}

This study is designed to have an in-depth understanding of short-term clinical oversea internship of nursing students in the U.S. to analyze its substance and meaning. As a result, the researchers found out 152 themes, 24 theme clusters, and five categories.

The first category is the "reliable hospital system," which is fully computerized and helps nurses to use the barcode to administer medication and to care only a small number of patients during their working hours. Therefore, the participants strictly followed the principles when nursing the patients with the system [4]. Also, on one hand, they were surprised when seeing medical consumables, which were mostly disposable products, single patient rooms, and rigorous infection management systems. On the other hand, they hope to see such system in Korea as well.

The second category is the "environments where nurses can demonstrate competence as professionals." Under such free atmosphere, nurses wore casual outfits and each nurse took care of less than four patients in the hospital. Therefore, they were able to perform an easy but holistic nursing to care physical, mental, and other aspects of patients. The same has been shown in the other researches [5][6]. The participants witnessed that nurses working in such environments received unwavering trust from patients and doctors. However, in Korea working environment in the hospital is poor. Hospitals standing the first grade of nursing, which is calculated by the number of nurses per patient, account for less than 10 percent in Korea [7]. However, even at such the first-grade hospitals, nurses cannot address physiological functions and skip their meals when they have unexpected emergent patients, not to mention their daily routine work to be performed within their working hours [8]. In that case, a holistic nursing is impossible in reality. Moreover, in the midst of conflict with patients or doctors, nurses face more exhaustion [9]. That is another important factor behind high turnover rates of nurses [10]. Therefore, the researchers believe that creating an environment where nurses can show their ability as a professional would be a key solve the issue of lack of clinical nurses as the participants felt during their internship in the U.S. Therefore, it is necessary to consider the medical fees and facilitate a liberal hospital environment by phase so that nurses can show their capability as a professional.

The third category is "Hospital environment to work." Participants who have been familiar with the hazing practice, called "taewoom" in Korea, felt a huge cultural gap and were shocked when experiencing the hospital environment where nurses treated newly joined nurses or nursing students as human beings and respect them. In fact, most of the newly joined nurses selected the "taewoom" practice of their seniors and "inhumane treatment" as the important reason behind their turnover [10]. Therefore, even before starting the clinical training as a professional nurse, students become depressed and have low confidence and selfesteem as a nurse during the clinical training [9]. Even the "taewoom" practice is being considered to be inappropriate and addressed in the field of clinical practice [10]. Therefore, it is imperative to improve its organizational cultures so that nursing students can have high self-esteem and practice clinical training.

The fourth category is the "motivation for learning." Participants built their attitude to more actively engage in the training while being respected and experiencing clinical training 
in an excellent environment [4]. While doing so, they felt sad that they were not able to learn more due to lack of their knowledge as well as English skills [5]. In order to foster talented nurses, a simple cramming and Spartan education have limitation [11]. Rather, such oversea internship programs provide nursing students motivation to learn and an important opportunity to improve themselves based on their own experience [12][13].

The fifth category is "the frog that came out of the well." The participants have experienced the international internship after going through the clinical training in Korea. Most of them were able to expand their vision while experiencing different hospital atmosphere from the field in Korea, its system, and nursing style through the internship [8][9]. Such changes are considered as one of the most significant outcomes of the short-term international internship. As other papers conducted on other professions showed that international internships provided the participants with an opportunity to have a bigger vision and dream [14][15], it is considered that such experience provides significant relevance.

\section{Conclusion}

This study was conducted on college students majoring in nursing, who have experienced a four-month internship abroad, to examine the meaning and substance of their international internship and have an in-depth understanding. As a result of analyzing its meaning, five categorizes were found. The concept identified by this study is to improve the level of the internship process and satisfaction, and going further, to lay the foundation for quality improvement of nursing education.

\section{References}

[1] D. Emstrong and L.P. Jones, "A broadened horizon: The value of international social work internships," Social Work Education, vol.26, no.2, pp.136-145, (2007)

[2] K. Cusher and J. Mahon, "Overseas student teaching: Affecting personal, professional, and global competencies in an age of globalization," Journal of Studies in International Education, vol.6, no.1, pp.44-58, (2002)

[3] C.K. Min and C. Shin, "A study on the relationship between the intention to participate in overseas internship and intercultural sensitivity and language ability of tourism majors," International Journal of Tourism and Hospitality Research, vol.39, no.9, pp.207- 220, (2015)

[4] H.W. Lee, "Investigating factors of successful overseas internship program for nurturing global talent," The Korean Journal of Human Resource Development, vol.13, no.1, pp.139-162, (2011)

[5] J.W. Kim, "Medical students' perceptions about international clinical electives in Korea," M.S. thesis, Hanyang University, Seoul, (2012)

[6] S.K. Kang, "Qualitative study on experience of social work practicum in overseas," Journal of Global Social Welfare, vol.2, no. 1, pp.31-66, (2012)

[7] K.S. Seo and J. A. Kim, "Clinical practicum experience among south Korean nursing students in the u.s. hospitals," Journal of Qualitative Research, vol.18, no.1, pp.93-104, (2017)

[8] S. Kim, "Abroad clinical internship experience of nursing students," Journal of Daegu Health College, vol.33, pp.143-157, (2013)

[9] P.F. "Colaizzi, psychological research as the phenomenologist views it," In Ronald S. Valle \& Mark King (eds.), Existential-Phenomenological Alternatives for Psychology, Oxford University Press, pp.6, (1978)

[10] K.J. Hong and S.H. Cho, "Changes in nurse staffing grades in general wards and adult and neonatal intensive care units," Journal of Korean Clinical Nursing Research, vol.23, no.1, pp.64-72, (2017)

[11] J.S. Kang, "A qualitative research on turnover experience among hospital nurses," Asia-pacific Journal of Multimedia Services Convergent with Art, Humanities, and Sociology, vol.7, no.4, pp.751-768, (2017) 
[12] J.H. Kim and I.K. Kim, "A study on the emotional labor, burnout and turnover intention of clinical nurses," Journal of the Korean Data Analysis Society, vol.16, no.3, pp.1653-1667, (2014)

[13] S.H. Choeng and I.S. Lee, "Qualitative research on nurses experiencing teawoom," Korean Journal of Occupational Health Nursing, vol.25, no.3, pp.238-248, (2016)

[14] Y.M. Kim and H.Y. Park, "Current trends of teaching-learning methods in Korean undergraduate nursing education," Journal of Learner-Centered Curriculum and Instruction, vol.16, no.3, pp.945-966, (2016)

[15] H.W. Jun, “A study on plans for global human resource development in hotel and tourism sector," Northeast Asia Tourism Research, vol.13, no.1, pp.179-201, (2013) 